\title{
Reward, Motivation and Creativity: Moderated By the Need for Power
}

\author{
Harris Kwaku Duah ${ }^{1} \&$ Prince Opoku ${ }^{1}$ \\ ${ }^{1}$ School of Management, Overseas Eucation, Nanjing University of Posts and Telecommunication, Jiangsu \\ Province, China \\ Correspondence: Harris Kwaku Duah, School of Management, Overseas Eucation, Nanjing University of Posts \\ and Telecommunication, Jiangsu Province, China.
}

Received: January 3, 2019

Accepted: January 23, 2019

Online Published: January 29, 2019

doi:10.5539/ibr.v12n3p1

URL: https://doi.org/10.5539/ibr.v12n3p1

\begin{abstract}
Indeed, although many scholars and practitioners are interested in understanding how to motivate individuals to be more creative, whether and how rewards affect creativity remain unclear. Therefore, in this paperr we have examined how reward, motivation and creativity are moderated by the need for power. Specifically, the study examined how the anticipation of individually administered reward for knowledge or for skills (eg praise, recognition, reinforcement, awards, incentives, performance pay plans) was linked to the employee creative performance in the workplace with intrinsic motivation as a mediating variable of this relationship and the need for power as a moderating variable of the relationship between intrinsic motivation and creativity. Questionnaire as research instrument was used and was distributed to 301 employees from Zhongxing Telecommunication Equipment (ZTE), Baidu, Roche, along with other 6 enterprises was used. In total, 275 usable responses were analyzed through SPSS. Standard procedures were used to process and represent findings. Pearson correlation analysis and multiple regressions were then applied to test the hypotheses. Findings - The study reaches three main conclusions. First, reward for knowledge and reward for skills are positively related to employee creativity. Second, intrinsic motivation mediates the relationship between reward for knowledge and for skills with creativity. Third the need for power moderates the relationship between the intrinsic motivation and employee's creativity such that individuals with a high need for power will exhibit intrinsic motivation for a greater creativity when reward for knowledge or reward for skill is high.
\end{abstract}

Keywords: reward for knowledge, reward for skills, creativity, intrinsic motivation; need for power

\section{Introduction}

Creativity has become a critical success factor for organizations in today's rapidly changing business environment (Amabile, Conti, Coon, Lazenby \& Herron, 1996; Ford and Gioia, 2000). Given the important role of employee creativity in the organization, researchers have become increasingly interested in identifying the conditions that predict creativity of individual employees. However, the need for creative problem solving has arisen as more and more management problems require creative insights in order to find appropriate solutions. Therefore, many researchers and practitioners are interested in understanding how to motivate individuals to be more creative. Anderson, Potoc, \& Zhou (2014) argued that the motivation of employees and their productivity can be enhanced through providing them effective recognition which ultimately results in improved performance of organizations. Rewards play a key role in generating motivation and thus are a critical component of organizational efforts to encourage creativity (Atchison, 2003).

Typically, rewards are used as a form of extrinsic motivation. Studies have it that non financial rewards are highly effective in motivating employees to higher performance. Indeed, the employees are willing to increase their work effort in order to obtain a specific need or desire that they hold (Beardwell \& Claydon, 2007, p. 491). This need is none other than the "need for power" in this paper. Employers are looking for high powers, these individuals who are intrinsically motivated to perform tasks and influence others, who enjoy competition, who are likely to tap every opportunity to achieve their needs, with creativity appearing to be a way of meeting these needs. Therefore, having a clear target and goal for business, it takes risk taker and eager employees to work out the best end result rapped in creativity. So it is very important to process the applicants' level of need for power to escort professional competences' formation with needed psychological competences in the circle. 
The aim of this study is to examine how reward, motivation and creativity are moderated by the need for power. The results will provide advice on whether and how rewards, intrinsic motivation and the need for power should further support creativity. We will open first up a discussion of the differing theoretical positions, including their historical background, followed by a description of their associated methodological differences that may be responsible for the difference in the findings. We will then present the audit of the literature, informed by these procedural differences, that brings order and regularity to the findings, and conclude with practical implications and suggestions.

\section{Theoretical Background and Model}

Researcher has studied employee creativity in recent decades because they offer more positive results that benefit individuals and organizations (Amabile, Conti, Coon, Lazenby \& Herron, 1996, Ford and Gioia, 2000, Armstrong and Murlis, 2007). Individual creativity can be the starting point and a prerequisite for organizational innovation (Amabile Amabile, Conti, Coon, Lazenby \& Herron, 1996). However, the diverse and often contradictory results of research and the concrete examples of the relationship between reward systems and creativity have led scholars to conclude that, although reward systems can influence creative behavior, the success of the program will be significantly influenced by certain factors. Such as the type of creativity required to solve the problem will influence the outcome of the reward system (Azar \& Shafighi, 2013). Second, the source of individual or group motivation to be creative can also determine the effectiveness of a reward system. Third, what type of creativity is desired, an incremental adaptation or a radical breakthrough in creativity? However, an extensive research on motivation precisely the intrinsic motivation will be done to demonstrate that reward systems can effectively impact creativity in individuals, groups, and organizations. We have chosen intrinsic motivation because is an important factor for creativity. Indeed, intrinsic motivation has emerged as such a core antecedent, which could stimulate employees to expend relatively enduring levels of involvement due to interest, curiosity, and a desire to learn (Deci \& Ryan, 2000). Consequently, intrinsic motivation theory has been heavily relied on (Amabile, 1996) in extant creativity study. However, intrinsic motivation within a context tends to be enhanced when people get their psychological needs met within that context (Deci \& Ryan, 2000). Therefore, an extensive research on the moderating role of need for power in the relation between intrinsic motivation and creativity will be also made such that high levels of the need for power will increase intrinsic motivation for a greater creativity when reward is high. Drawing from several bodies of literature, we suggest a simple model of reward systems and creativity. We examine two aspect of reward: reward for knowledge plus reward for skills, also intrinsic motivation as a mediator and the need for power as a moderator of the relationship between reward (reward for knowledge and reward for skill) and employee creativity.

\subsection{Reward and Creativity}

Creativity has been highly valued as it is considered to be a good predictor of invention (Amabile, 1997; Armstrong and Murlis, 2007) and, as such, crucial for companies if they are to continue to grow and to prosper (DeVamia \& Tichy, 1990). Employee creativity has been introduced as the foundation for organizational innovation in order to attain competitive advantage (Armstrong and Murlis, 2007; Zhang \& Bartol, 2010). Consequently, today's managers face the challenge of creating the conditions necessary for such creativity to flourish (Mumford, Scott, Gaddis, \& Strange, 2002). Indeed, studies examining the effects of different instructions on creativity (e.g., "be creative" versus "be practical") indicate that participants respond more creatively when asked to be creative than when not so asked (Amabile, 1979; O'Hara \& Sternberg, in press). For example, when asked to generate solutions to human resource management problems, Armstrong and Murlis (2007) found that the highest creativity occurred when participants had a creativity goal and worked alone under evaluation expectations.

We define creativity as the production of ideas, products, or procedures that are novel or original and potentially useful to the organization. According to Pirola-Merlo and Mann (2004), Creativity has been defined as a judgment of the novelty and usefulness (or value) of something. Similarly, Sternberg and Lubart (1996) stated that creativity is 'the ability to produce work that is both novel (i.e., original, unexpected) and appropriate (i.e., useful, adaptive concerning task constraints)' (p. 3). And finally, Martindale (1989) opined that creativity 'must be original, it must be useful or appropriate for the situation and it must actually be put to some use' (p. 211). In light of the common themes in these definitions, it seems that the value of creativity in organizations may pertains to an ability to exploit new yet suitable ideas to the end of improving organizational efficiency, solving complicated problems and increasing overall effectiveness.

However, personal creativity is demonstrated when an individual has the necessary knowledge and skills to perform a task, and an individual's skills and knowledge to perform such tasks are demonstrated by patterns of 
behavior. Indeed, Knowledge is a critical driver of creativity. In other hand individual's skill level may also help to facilitate creative performance. For example, in a complex job environment in which job tasks demand a high-level of involvement and creativity, a person can solve difficult problems by using personal knowledge, intelligence, and experience (skill). Amabile (1996) theory, found that domain-relevant knowledge, creativity-relevant skills and motivation are the three intra- individual factors influencing creativity. Employees with the necessary skills are able to demonstrate consistent patterns of behavior in their work and are likely to perform many essential duties at or above the standard required (Dierdorff and Surface, 2008). Accordingly, employees with greater degrees of factual knowledge, technical skills, and special talents and/or greater tendency to process cognitive information in intuitive and flexible ways are likely to display higher frequency and levels of creativity.

Individual skills and behaviors can be inferred from job tasks, while knowledge is acquired through education and work experience according to Competency advocates (Armstrong and Murlis, 2007). However, as an effort to stimulate employees' creativity, many managers have used extrinsic rewards (e.g. monetary incentives and recognition) to motivate their employees (Fairbank and Wiliams, 2001; Van Dijk and Van den Ende, 2002). We define reward as something that is given in return for good or evil done or received or that is offered or given for some service or attainment. According to Nationalencyklopedin (2015) reward is either money or honour that pays out as compensation, normally as a sign of appreciation or achievement. It is the benefit that arise from performing a task, rendering a service or discharging a responsibility according to Colin (1995). In addition, reward systems based on personal knowledge can result in higher levels of creativity. Similarly, reward systems based on skills can do the same. Indeed, rewards are an effective motivator for various kinds of performance including creativity (Creativity scholars and laypersons). Employees are more likely to be motivated to perform when they perceive that there is a strong link between their performances and the reward they receive (Fey and Bjorkman, 2001; Guest, 2002; Mendonca, 2002). Employees will give their maximum when they have a feeling or trust that their efforts will be rewarded by the management. In exchange for the rewards provided to them, employees will reciprocate by increasing their commitment towards their organization and their work.

According to Eisenberge (1992), extrinsic rewards help to enhance individualse creative performance. Coincidentally, empirical research has shown that those who receive a reward are more creative than those who have not received it. It's for example the case of research by Eisenberger and Rhoades (2001) which showed that students who were promised rewards for being creative produced more creative movie titles than did students who were not promised rewards. In a follow-up study, Eisenberger and Aselage (2009) replicated the positive effect of reward on creativity and provided further evidence to support their claim that contingent rewards can enhance perceptions of self-determination and intrinsic motivation. Specifically, their results showed that rewards for higher performance (i.e., being offered 10 dollars if their story titles were judged to be better than those of $80 \%$ of the past participants) created performance pressure - a negative or aversive affective state associated with dissatisfaction with their current progress towards desired goals - and perceptions of self-determination, which in turn enhanced intrinsic motivation and creative performance. Specifically, these authors argued that performance-contingent rewards induce commitment to the objective of achieving higher standards of performance, which produces discomforting pressure for the necessity of higher performance. Individuals are more thoughtful, willing to depart from routine, and employ diverse skills in order to alleviate the negative experience of performance pressure (Eisenberger \& Aselage, 2009).

The results showed that students in rewarded conditions experienced greater self- determination and intrinsic motivation and, as a result, exhibited greater creativity in story titles compared with students in the non-rewarded condition.

Eisenberger, Armeli, \& Pretz (1998), have argued that rewarding individuals is a signal of good performance, and provides encouragement to the employee to continue exhibiting the behaviors that have been recognized. At the same time, the mere lack of providing a reward can signal to lower performing individuals that their performance must improve. Indeed, Bentham stated that "Nature has placed mankind under the governance of two sovereign masters, pain and pleasure." The behaviorists showed the power of reward to influence many aspects of human performance. So it seems natural to suppose that creativity, as with other human activities, can be enhanced by reward.

\section{Hypothesis1: reward for knowledge and reward for skills implementation is positively related to creativity} outcome.

\subsection{Mediating Role of Intrinsic Motivation}

Human resource provides basis for an organization to achieve sustainable competitive advantage. Since 
organizations are operating in a dynamic and competitive business environment, they need to develop strategies to acquire and retain the skilled workforce. Nowadays, human asset considered to be the most important asset of any organization and in order to get the efficient and effective result from human resource motivation is necessary. Indeed, Being the key that gets people to do what they do, motivation have been valued to be the basic conception of the effect of reward on creativity. Reward systems are designed to motivate specific behaviors. A vast body of work on motivation has developed over the past 50 years, so it is worthwhile to investigate the link between creativity and reward systems through the perspective of the motivation. Brief reflection suggests that motivation is hardly a unitary phenomenon. People have not only different amounts, but also different kinds of motivation. That is, they vary not only in level of motivation (i.e., how much motivation), but also in the orientation of that motivation (i.e., what type of motivation). This natural motivational tendency is a critical element in cognitive, social, and physical development because it is through acting on one's inherent interests that one grows in knowledge and skills. Therefore, individuals may respond differently to the same reward depending on their psychological reactions. Specifically reward for knowledge and reward for skills are expected to affect the creativity of employees by shaping their task motivation, thus suggesting the intervening role of motivation between reward and creativity. No surprisingly then, scholars have invested much effort seeking for the relevant psychological forces. Intrinsic motivation has emerged as such a core antecedent, which could stimulate employees to expend relatively enduring levels of involvement due to

interest, curiosity, and a desire to learn (Deci \& Ryan, 2000). Consequently, intrinsic motivation theory has been heavily relied on (Amabile, 1996) in extant creativity study. Researchers pointed out that task motivation is ephemeral, and thus, susceptible to contextual factors (Hennessey \& Amabile, 1999). The bulk of study demonstrates intrinsic motivation triggers higher levels of creativity (Amabile, 1985; Janssen \& van Yperen, 2004; Shin \& Zhou, 2003). Hence, this study focuses on intrinsic motivation. Many researchers have reflected on an intrinsic motivational orientation as an important factor in creativity (Amabile, 1990; Barron \& Harrington, 1981). Indeed, several scholars have argued that high intrinsic motivation (i.e., the individual is excited about an activity and engages in it for the sake of the activity itself) is a necessary ingredient for creative achievement (Amabile, 1996; Armstrong and Murlis, 2007). Individuals are likely to be most creative when they experience high levels of intrinsic motivation (Amabile, 1996; Audia \& Goncalo, 2007; Armstrong and Murlis, 2007).

However, we defined intrinsic motivation as doing something because it is inherently interesting or enjoyable. According to Herzberg (1957), intrinsic motivation is the self-generated factors that influence people to behave in a particular way or to move in a particular direction. These factors include responsibility (feeling that the work is important and having control over one's own resources), autonomy (freedom to act), scope to use and develop skills and abilities, interesting and challenging work and opportunities for advancement. The power of intrinsic motivation is so strong that simply thinking about intrinsic reasons for doing a task may be sufficient to boost creative on that activity. Longitudinal investigation of art students found that those whose Thematic Appreciation Test (TAT) pictures had a good deal of intrinsic imagery highlighting the joy of creating art-persisted in the field after their schooling and were more likely to achieve eventual success. Amabile (1996) has argued that Intrinsic motivation has been recognized as a key predictor of individual creativity because the challenge and enjoyment of the work itself promote persistence, exploration, and experimentation that often lead to creative outcomes. Interactionist model of creative behavior also acknowledged intrinsic motivation as a component of the individual that is conduct to creative accomplishment (Hennessey \& Amabile, 1998). Moreover, both theoretical models and empirical studies are consistent with the notion that intrinsic motivation is conducive to creative performance.

Although various forms of rewards are generally expected to generate extrinsic motivation, the effects of rewards on intrinsic motivation remain controversial. According to Cognitive Evaluation Theory (Deci \& Ryan, 2000), offering extrinsic rewards to individuals who work on complex jobs that produce high intrinsic motivation should have detrimental effects on their subsequent intrinsic motivation and creativity. People enjoy having their accomplishment recognized by others, which can increase internal motivation. Eisenberger \& Rhoades (2001) based on the findings of the research conducted with college students, suggested that cognitive evaluation theory must be modified in order to assume that reward increases perceived self-determination and perceived competency, thereby increasing intrinsic motivation. Such heightened task interest may promote creativity. The positive relationship between reward expectancy and intrinsic task interest was greater among employees with a strong desire for control, indicating the importance of rewards as an indicator of self-determination (Eisenberger \& Rhoades, 2001).

Also, in a meta-analysis of 96 experimental studies measuring the effect of reward on intrinsic motivation, Cameron and Pierce (Cameron \& Pierce, 1994) found no consistent evidence that reward decreases intrinsic 
motivation; in fact, verbal praise appeared to increase intrinsic motivation. Sternberg and Lubart corrected an old misconception, explaining that extrinsic rewards such as grades or money that parents can promise or give to children for a specific achievement, do not necessarily affect negatively their work. Eisenberger, Pierce and Cameron (1999) developed general interest theory which criticizes the limitations of cognitive evaluation theory. This theory indicates that the content of tasks and the context in which they are presented increases intrinsic motivation to the extent that they indicate that performing the task helps satisfying the needs, wants and desires. According to this theory, under certain conditions, extrinsic rewards can enhance intrinsic motivation. For example, when a gift certificate is given to an employee as a reward for good performance in a department-wide meeting, that employee may realize motivation not only by the receipt of a valuable item, but she may also experience an increase in intrinsic motivation from recognition of superior performance by her peers and supervisor.

Research suggests that rewards for novel performance increase intrinsic motivation and creativity (Eisenberger \& Aselage, 2009). Eisenberger and Armeli (1998) found that reward for giving unusual uses for common objects increased schoolchildren's intrinsic interest in creative activities; following reward on an unusual-use task, the children showed a preference for a new creative task (drawing novel pictures) over a conventional task (copying an old picture). Hennessey and Amabile (1998) pointed out that "rewards can actually enhance intrinsic motivation and creativity when they confirm competence, provide useful information in a supportive way, or enable people to do something that they were already motivated to do" (p. 581). Also Deci, Koestner and Ryan (1999) noted that when rewards were given independently of any task engagement, as is the case with an employee's salary, and if these rewards were not expected, such as unanticipated bonuses and monetary rewards had a positive association with intrinsic motivation. Employees were satisfied and more intrinsically motivated to give a high quality performance.

\section{Hypothesis 2: intrinsic motivation mediates the relationship between reward for knowledge and creativity;}

\section{Hypothesis 3: intrinsic motivation mediates the relationship between reward for skills and creativity.}

\subsection{The Moderating Role of Need for Power}

Have you ever heard that the reward systems for the creative performance are only effective if the intrinsic needs of the employee have been met?, so that the high level of this need increases intrinsic motivation in order to boost creative performance. Förster, Friedman, Özelsel and Denzler (2006) have argued that having power leads to approach motivation with its concomitant global attentional focus. Indeed, according to SDT, intrinsic motivation within a context tends to be enhanced when people get their psychological needs met within that context (Deci \& Ryan, 2000). The intrinsic motivation is considered to have its roots in the basic human needs for capacity, challenge and control, for interest of individual is considered to be developed from internal sources that are consistent with external influences. Therefore, the framework adopted for this study is based on the need for power which moderate the relation between intrinsic motivation and creativity. Individual needs for power are well recognized motivator of human behavior (McClelland, 1987). Research on personality (House, 1988; Alpander, 1991) has shown that the need for power control is one of the strongest and most deeply ingrained human needs. According to Robbins (2005), a need is an internal state that makes certain outcomes appear attractive; an unsatisfied need creates tension that stimulates drives within an individual. The need for power is defined as the desire to control or influence others McClelland (1987). From the objective point of view, individuals with a high need for power (nPow) tend to be ambitious and believe that they have influence over work outcomes. They attempt to gain control over their work environment and seek positions of authority and status. They are also more likely to win in organizational competitions (e.g., sales competitions) because they take more active roles in controlling their work schedules and attracting others' recognition, resulting in higher productivity and better work results (Hon \& Rensvold, 2006). Therefore, people with a high need for power are intrinsically motivated to perform tasks. They are likely to tap every opportunity to achieve their needs, with creativity appearing to be a way of meeting these needs.

Individuals with high need for power are more likely to adopt creative roles in the workplace. Indeed, in workplace, powerful individuals are more likely to be creative than their less powerful counterparts, who are left with little incentive to be creative. When creative performance is functionally relevant to one's power position, we would thus expect more creativity than when creative performance is functionally irrelevant. An example of such functionally relevant creativity is when a middle-manager of a company is facing decreasing revenues, and new and creative ideas are needed to turn the situation around. By solving the company's problems in creative ways (e.g., through introducing new products or services, or by increasing market share through creative marketing) a manager can show high competence and may as a consequence be promoted to a higher position. In 
the same way, McClelland (1987) has claimed that the top manager is the one who have a high need for power.

From the psychological point of view, high-nPow individuals believe that they are powerful, capable, and able to control their work set- tings (McClelland, 1987). People are unlikely to feel the need for something they feel incapable of using; thus, high nPow individuals are more likely to master power and to feel capable of shaping their work and work environments (Hon \& Rensvold, 2006). As they are aware of power, people with a high nPow are more likely to exhibit creative performance than those with a low nPow. Beardwell \& Claydon, (2007), have argue that employees are willing to increase their work effort in order to obtain a specific need or desire that they hold. In this way, powerful people may display the highest creativity levels under conditions where creativity allows them to maintain or increase their power. As a result, because creativity will be a way for these individuals to maintain their power position, they will then be more likely to be creative than those who do not have a need for power.

Considering all that has been said previously and relying on the fact that some studies show that power leads to increased creativity (Galinsky, Magee, Gruenfeld, Gruenfeld and Whitson, 2008, Smith \& Trope, 2006). We can suppose that need for power moderate the relation between intrinsic motivation and creativity, hence the following hypothesis:

\section{Hypothesis 4: need for power moderates the relationship between intrinsic motivation and creativity.}

\section{Method}

\subsection{Sampling}

For the purpose of this research, a Scientific and technological enterprises have been selected. The reason for selecting these sectors is that these enterprises featuring high need for creativity in industries. Therefore, our sample, was constituted of 301 employees which are working in communication service, internet service, scientific research and technological service from Zhongxing Telecommunication Equipment (ZTE), Baidu, Roche, along with other 6 enterprises.

\subsection{Procedure}

The data collected for this research is gathered through a questionnaire. Indeed, 301 copies of questionnaires are distributed in Shanghai and Shenzhen through express delivery. The questionnaire had two versions one in English and another in Chinese to facilitate the task of filling the questionnaire to all our participants either being international or local. However, it's important to note that all the measurement scale was originally in English thus them being translated in Chinese by Marina one of this thesis assistants. Consideration was given to demographic factors such as gender, degree of education, age, occupation, and years of working and average monthly income of participants during the selection. Except for demographic questions, the questionnaire format had 5 points response structure for all the study measurement ranging from: 1(Strongly Disagree) 2 (Disagree), 3 (Not Sure), 4(Agree), 5(Strongly Agree). The participants were told that the survey was voluntary. To ensure that their responses remained anonymous, the respondents were asked not to writing their names on any part of the survey form and were informed that their individual responses would not be disclosed or reported. The participants were asked to assess the extent to which their reward systems were aligned with their competence, creative performance, motivation and psychological needs for power. After one week all questionnaires was return. Of 301 questionnaires distributed, 26 were invalid and excluded from subsequent analysis due to seriously incomplete or contradictory answers. Therefore, the valid questionnaires reach the number of 275 , making the effective recovery rate $91 \%$.

\subsection{Time Horizon}

On an average time of two weeks, individuals were invited to complete questionnaire based survey measuring their work style." Initially for a normal completion it would take like 5 to 7 minutes on each questionnaire for each person to fill it up.

\subsection{Measures}

The constructs in this study were measured using multi- item scales well-published with acceptable levels of reliability. For all the study measurement explained in the following, the response structure ranging from: 1(Strongly Disagree) 2 (Disagree), 3 (Not Sure), 4(Agree), 5(Strongly Agree).

\subsubsection{Reward for Knowledge and Reward for Skills (Independent Variables)}

Reward for knowledge and for skill are a new concept which are not widely developed in the writing. To measure respondents' perceptions of the extent to which the organizational reward system was linked to their knowledge and skills, we built up new scales of eight elements. In view of compensation its definitions, a 
12-thing scale relating to representatives' impression of authoritative prizes connected with their capability was initially formed. To ensure the validity of this scales, an exploratory component examination (EFA) of the 12 things was directed utilizing varimax turn and factor loading with eigenvalue bigger than one.

The result in Table below demonstrate that the component loading was affirmed for just two unmistakable components, with the four items of the first elements measuring pay or rewards identified with people's information, knowledge, and education level being named reward for knowledge. The simple items include "I know that in my company a knowledgeable gets promoted first", "I fell my pay or bonus is a good reflection of my education level and qualification". The second set of elements, named reward skills included four items measuring work performance, capability, and employee skills. The simple items include "If I have the skills to fulfill responsibilities specified in my job description I would expect a pay"; I can perform many essential duties". The four remaining items neglected to stack on a single element and were deleted to keep up the internal validity of each element. The component loadings extended from .67 to .95 , and the two components collectively accounted of $70 \%$ of the variance. The coefficient alpha for CBP for knowledge was .74 and that for CBP for capability was .91 .

\subsubsection{Intrinsic Motivation (Mediating Variable)}

For this variable, Guay et al. (2000) four-item scale was used. The coefficient alpha for this four-item scale was .94. Sample items include "I usually work or engage in task activities in this company because (a) I think that the activity is interesting, (b) I think that the task activity is pleasant, (c) the activity is fun for me, and (d) I feel good when doing the activity.

\subsubsection{Need for Power (Moderating Variable)}

The measure used by Parker and Chusmir's (1991) was adopted to assess need for power. Specifically, five-item scale was used. The coefficient alpha for this five-item scale was 72. Sample items include "I enjoying competition and winning"; "I enjoying being in charge"; "I confront people who do things I disagree with"; "I enjoying influencing other people to get my way"; I often work to gain more control over the events around me".

\subsubsection{Creativity (Dependent Variable)}

Employee Creativity was measured with 6 items adopted from Nadjar N, Greenberg E and Chen Z (2011). The coefficient alpha for this six-item scale was .76. Sample items include "Is a good source of highly creative idea"; "demonstrates originality in his /her work"; "suggests radically new way for doing advertising"; "uses previously existing ideas or working an appropriate new way; is very good at adapting already existing ideas or ads"; "easily modifies previously existing work processes to suit current needs".

\section{Results and Analysis}

\subsection{Demographic Analysis}

Several type of demographic information were collected as the description of our sample. Descriptive statistics from the statistical analysis program of SPSS was used to calculate frequencies of each demographic variable. A total of 275 responses were used in the analyses. About $55.6 \%$ of participants were male and $44.4 \%$ were female. $13.8 \%$ were below the age of $25 ; 37.8 \%$ were between the ages of 25 and $29,39.6 \%$ were between 30 and 39 ; $5.8 \%$ were between 40 and 49 , and the rest of $2.9 \%$ were above 50 . As a degree of education $4.7 \%$ of the respondents had been educated to high school level or below; $63.3 \%$ had a bachelor's degree and $32 \%$ had a master degree or above. Also, $18.9 \%$ of employee were manager, $33.1 \%$ worked as technical personnel, $21.1 \%$ worked as a marketer, $8.75 \%$ worked as financial personnel and the rest (18.2\%) worked in other service. Of participant, $29.1 \%$ had worked for less than 3 years; $30.2 \%$ had worked for 3 - 6 years; $34.9 \%$ had worked for 7-14 years; and 5.8\% had had worked for more than 15 years. About monthly average income of participant, $8 \%$ had less than 5 thousand by month, 30.9\% had monthly average between 5 and 10 thousand; $40.4 \%$ of participant had between 10 and 20 thousand, $12.4 \%$ had between 20 and 30 thousand and 8.4 had more than 30 thousand a month. 
Table 1. demographic profile of participants

\begin{tabular}{|c|c|c|c|c|c|}
\hline & Valid & Frequency & Percent & $\begin{array}{l}\text { Valid } \\
\text { Percent }\end{array}$ & $\begin{array}{c}\text { Cumulative } \\
\text { Percent }\end{array}$ \\
\hline \multirow{3}{*}{ Gender } & Male & 153 & 55.6 & 55.6 & 55.6 \\
\hline & female & 122 & 44.4 & 44.4 & 100.0 \\
\hline & Total & 275 & 100.0 & 100.0 & \\
\hline \multirow{6}{*}{ Age } & Below25 & 38 & 13.8 & 13.8 & 13.8 \\
\hline & $25-29$ & 104 & 37.8 & 37.8 & 51.6 \\
\hline & $30-39$ & 109 & 39.6 & 39.6 & 91.3 \\
\hline & $40-49$ & 16 & 5.8 & 5.8 & 97.1 \\
\hline & Above 50 & 8 & 2.9 & 2.9 & 100.0 \\
\hline & Total & 275 & 100.0 & 100.0 & \\
\hline \multirow{4}{*}{$\begin{array}{l}\text { Degree of } \\
\text { education }\end{array}$} & high school or below & 13 & 4.7 & 4.7 & 4.7 \\
\hline & Bachelor or & 174 & 63.3 & 63.3 & 68.0 \\
\hline & undergraduate & 88 & 32.0 & 32.0 & 100.0 \\
\hline & $\begin{array}{l}\text { master or above } \\
\text { Total }\end{array}$ & 275 & 100.0 & 100.0 & \\
\hline \multirow{7}{*}{ Occupation } & Manager & 52 & 18.9 & 18.9 & 18.9 \\
\hline & technical & 91 & 33.1 & 33.1 & 52.0 \\
\hline & personnel & 58 & 21.1 & 21.1 & 73,1 \\
\hline & Marketers & 24 & 8.7 & 8.7 & 81.8 \\
\hline & Financial personnel & 50 & 18.2 & 18.2 & 100.0 \\
\hline & Else & 275 & 100.0 & 100.0 & \\
\hline & Total & & & & \\
\hline \multirow{5}{*}{ Years of working } & less than 3 years & 80 & 29.1 & 29.1 & 29.1 \\
\hline & 3-6 years & 83 & 30.2 & 30.2 & 59.3 \\
\hline & $7-14$ years & 96 & 34.9 & 34.9 & 94.2 \\
\hline & more than 15 years & 16 & 5.8 & 5.8 & 100 \\
\hline & Total & 275 & 100.0 & 100.0 & \\
\hline Monthly & less than 5 thousand & 22 & 8.0 & 8.0 & 8.0 \\
\hline Average & $5-10$ thousand & 85 & 30.9 & 30.9 & 38.9 \\
\hline \multirow[t]{4}{*}{ income } & $10-20$ thousand & 111 & 40.4 & 40.4 & 79.3 \\
\hline & 20-30 thousand & 34 & 12.4 & 12.4 & 91.6 \\
\hline & more than 30 & 23 & 8.4 & 8.4 & 100 \\
\hline & $\begin{array}{l}\text { thousand } \\
\text { Total }\end{array}$ & 275 & 100 & 100 & \\
\hline
\end{tabular}

\subsection{Validity and Reliability}

Reliability and validity refer to the degree to which an instrument measures what it purports to be measuring (Cronbach \& Meehl, 1955). The issue of reliability and validity has been of great concern to many researchers. Most researchers deem reliability and validity important concepts in research as a means of portraying if a study is worth giving attention.

Convergent validity ensures that the measures of each construct are highly correlated while discriminant validity ensures that there is a low correlation between the measures of different constructs (Gefen, Straub \& Marie-claude., 2000). To assess the convergent validity of a questionnaire, researchers have to examine the factor loading of each item and the reliability of each construct. As a rule of thumb, the factor loading of each item should load above 0.5 and must be significant; whereas the value of the construct reliability of each construct should be greater than 0.7 (Nunnally \& Bernstein, 1994).

1. Validity analysis

To test the validity of the measurements we have used the explanatory factor analysis (EFA) test specifically the construct validity of the scales was explored using principal component analysis. The Kaiser-Meyer-Olkin (KMO) measure and Bartlett's test of sphericity were used to determine the suitability of the data for the procedure. Data was considered suitable if the KMO was greater than .50 and Bartlett's test of sphere city was significant. Only factors with eigenvalue greater than 1 were taken into account (Kaiser, 1970). 
Table 2. KMO and Bartlett's Test

Kaiser-Meyer-Olkin Measure of Sampling Adequacy.

Approx. Chi-Square

Bartlett's Test of Sphericity Df

Sig.

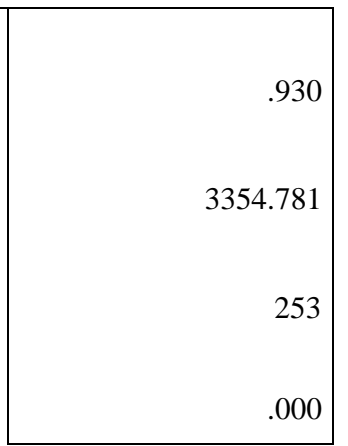

As showing in table 1, the KMO measure is more than .50 being .930 which is excellent; also all the components are significant, this means that the variables are correlated with each other indicating that the set of data is adequate and appropriate for EFA to be employed. Adding Bartlett's Test of Sphericity which is less than 0.05 being .002 we can say that the factor analysis is suitable.

Table 3. Total Variance Explained

\begin{tabular}{|c|c|c|c|c|c|c|c|}
\hline \multirow{2}{*}{ Components } & \multicolumn{3}{|c|}{ Initial Eigenvalues } & \multicolumn{3}{|c|}{$\begin{array}{c}\text { Extraction Sums of Squared } \\
\text { Loadings }\end{array}$} & \multirow{2}{*}{$\begin{array}{l}\text { Rotation } \\
\text { Sums of } \\
\text { Squared } \\
\text { Loadings } \\
\text { Total }\end{array}$} \\
\hline & Total & $\begin{array}{c}\% \text { of } \\
\text { Variance }\end{array}$ & $\underset{\%}{\text { Cumulative }}$ & Total & $\begin{array}{c}\% \text { of } \\
\text { Variance }\end{array}$ & $\underset{\%}{\text { Cumulative }}$ & \\
\hline 1 & 9.525 & 41.411 & 41.411 & 9.525 & 41.411 & 41.411 & 4.465 \\
\hline 2 & 1.787 & 7.769 & 49.180 & 1.787 & 7.769 & 49.180 & 3.872 \\
\hline 3 & 1.528 & 6.643 & 55.823 & 1.528 & 6.643 & 55.823 & 3.129 \\
\hline 4 & 1.316 & 5.721 & 61.544 & 1.316 & 5.721 & 61.544 & 2.689 \\
\hline 5 & .831 & 3.613 & 65.157 & & & & \\
\hline 6 & .770 & 3.349 & 68.506 & & & & \\
\hline 7 & .744 & 3.233 & 71.739 & & & & \\
\hline 8 & 679 & 2.952 & 74.691 & & & & \\
\hline 9 & .631 & 2.744 & 77.435 & & & & \\
\hline 10 & .575 & 2.501 & 79.936 & & & & \\
\hline 11 & .546 & 2.373 & 82.310 & & & & \\
\hline 12 & .501 & 2.177 & 84.486 & & & & \\
\hline 13 & .449 & 1.953 & 86.439 & & & & \\
\hline 14 & .425 & 1.848 & 88.287 & & & & \\
\hline 15 & .397 & 1.725 & 90.012 & & & & \\
\hline 16 & .372 & 1.618 & 91.630 & & & & \\
\hline 17 & .350 & 1.520 & 93.150 & & & & \\
\hline 18 & .326 & 1.419 & 94.569 & & & & \\
\hline 19 & .284 & 1.236 & 95.805 & & & & \\
\hline 20 & .280 & 1.216 & 97.021 & & & & \\
\hline 21 & .259 & 1.127 & 98.148 & & & & \\
\hline 22 & .238 & 1.033 & 99.182 & & & & \\
\hline 23 & .188 & .818 & 100.000 & & & & \\
\hline
\end{tabular}

Extraction Method: Principal Component Analysis.

The table 3 demonstrate how the variance is divided among 23 possibles factors. In this case four factors have eigenvalues (a measure of explained variance) greater than 1.0 which means that 4 variables were extracted with a total variance explained of $61.544 \%$ which is more than a half of the 23 indicating that the four factors are useful. 
Table 4. Rotated Component Matrixa

\begin{tabular}{|c|c|c|c|c|}
\hline & & & onent & \\
\hline & 1 & 2 & 3 & 4 \\
\hline$\overline{\mathrm{Q} 16}$ & .781 & & & \\
\hline Q15 & .768 & & & \\
\hline Q17 & .764 & & & \\
\hline Q18 & .692 & & & \\
\hline Q13 & .681 & & & \\
\hline Q14 & .678 & & & \\
\hline Q31 & .568 & & & \\
\hline Q30 & .513 & & & \\
\hline Q32 & & & & \\
\hline Q33 & & & & \\
\hline Q28 & & .365 & & \\
\hline Q34 & & .512 & & \\
\hline Q29 & & .740 & & \\
\hline Q35 & & .738 & & \\
\hline Q41 & & .681 & & \\
\hline Q42 & & .671 & & \\
\hline Q43 & & .640 & & \\
\hline Q40 & & .598 & & \\
\hline Q44 & & & & \\
\hline Q47 & & & .806 & \\
\hline Q48 & & & .787 & \\
\hline Q46 & & .302 & .751 & \\
\hline Q45 & & & .695 & \\
\hline & & & .451 & \\
\hline & & .330 & & .309 \\
\hline & & & & .823 \\
\hline & & & & .795 \\
\hline & & & & .665 \\
\hline & & & & .632 \\
\hline
\end{tabular}

Extraction Method: Principal Component Analysis. Rotation Method: Varimax with Kaiser Normalization. a. Rotation converged in 6 iterations.

As it can be seen in table 4, the four variable extracted corresponding to the four variables of measurement:

$\checkmark$ Variable 1 (Q16...QQ18) corresponding to creativity performance;

$\checkmark$ Variable 2(Q28...Q31 and Q32... Q35)..............reward for skill and reward for knowledge;

$\checkmark$ Variable $3(\mathrm{Q} 40 \ldots \mathrm{Q} 43) \ldots \ldots \ldots \ldots \ldots \ldots \ldots \ldots \ldots$ intrinsic motivation;

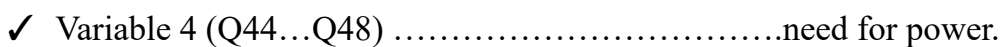

2. Reliability analysis

Reliability analysis refers to the extent to which a scale produces consistent results, if the measurements are repeated a number of time. It was used to measure the accuracy of the data collected, to ensure that all items used in each variable were free from errors and thus, providing consistent results. To test the reliability of this research, the scales of this four variable was tested by using the Cronbrach's alpha. There are different reports about the acceptable values of alpha, ranging from 0.70 to 0.95. Hinton, Brownlow, McMurray and Cozens (2004) have suggested four cut-off points for reliability, which includes excellent reliability ( 0.90 and above), high reliability (0.70-0.90), moderate reliability (0.50-0.70) and low reliability (0.50 and below).

The Cronbrach's alpha for all the scales of dependent variable (employee creativity) was

.881 suggesting that the items have high reliability (Note that a reliability coefficient of .70 or higher is considered acceptable in research). The Cronbrach's alpha for all the scale of independent variable was .781 for reward for skill and .811 reward for knowledge. Next is the mediating variable (intrinsic motivation) with a Cronbrach's alpha of .870 showing that the results for this variable's items are high acceptable for a reliability measurement, finally is the moderating variable (need for power) with a Cronbrach's alpha .787. The result of reliability measurement of all variable was higher than .70 showing that the research has high and good 
reliability require for a good research. The tables below show and justify the above cronbash's alpha interpretation in a respective order:

Table 5. Reliability Statistics

\begin{tabular}{ccccc}
\hline & $\begin{array}{c}\text { Cronbach's } \\
\text { Alpha }\end{array}$ & $\begin{array}{c}\text { Cronbach's Alpha Based on } \\
\text { Standardized Items }\end{array}$ & N of Items & Indicator \\
\hline Reward for knowledge & .811 & .812 & 4 & High \\
Reward for skills & .781 & .780 & 4 & High \\
Creativity & .881 & .881 & 6 & High \\
Intrinsic motivation & .870 & .869 & 4 & High \\
Need for power & .787 & .785 & 5 & High
\end{tabular}

Above table shows the Cronbach alpha and items of each variables. The Cronbach"s coefficients alpha values for all factors that range from 0.781 to 0.881 indicated good inter-items consistency for each factor.

\subsection{Correlation Analysis}

The correlation analysis was done by using Pearson correlation. The result in this case demonstrate that we have a positive correlation between variables. As we see, independent variables (Reward of skill and Reward of knowledge) correlate positively with employee creative performance; specifically Reward of knowledge correlate positively with creativity performance (significantly at $\mathrm{r}(273)=.408 \mathrm{p}<0.01=0$ level) and reward of skill correlated with creativity performance at a level of $\mathrm{r}(273)=.404, \mathrm{p}<0.01=0$. These two dimensions of reward were positively correlated with the mediating point of motivation at a significant range level of $r$ (273) $=.344$ to $.450, \mathrm{p}<0.01$ and still this mediating variable itself had a good correlation with the dependent variable the creativity performance at a significant level of $\mathrm{r}(273)=.420, \mathrm{p}<0.01$. This same moderator was correlated positively with the moderating point need for power at the significant level of $r(273)=.450, p<0.01$. And still this moderating variable itself had a good correlation with the dependent variable the creativity performance at a significant level of $\mathrm{r}(273)=.208, \mathrm{p}<0.01$. All together, these positive correlations are shown in Table 6 below.

Table 6. correlations

\begin{tabular}{|c|c|c|c|c|c|c|}
\hline & & Crea & & RK & IMot & NPow \\
\hline \multirow{3}{*}{ Crea } & Pearson Correlation & 1 & $.404^{* *}$ & $.408^{* *}$ & $.420^{* *}$ & $.208^{* *}$ \\
\hline & Sig. (2-tailed) & & .000 & .000 & .000 & .001 \\
\hline & $\mathrm{N}$ & 275 & 275 & 275 & 275 & 275 \\
\hline \multirow{3}{*}{$\mathrm{RS}$} & Pearson Correlation & $.404^{* *}$ & 1 & $.423^{* *}$ & $.344^{* *}$ & $.205^{* *}$ \\
\hline & Sig. (2-tailed) N & .000 & & .000 & .000 & .001 \\
\hline & & 275 & 275 & 275 & 275 & 275 \\
\hline \multirow{3}{*}{ RK } & Pearson Correlation & $.408^{* *}$ & $.423^{* *}$ & 1 & $.450^{* *}$ & $.283^{* *}$ \\
\hline & Sig. (2-tailed) N & .000 & .000 & & .000 & .000 \\
\hline & & 275 & 275 & 275 & 275 & 275 \\
\hline \multirow{3}{*}{ IMot } & Pearson Correlation & $.420^{* *}$ & $.344^{* *}$ & $.450^{* *}$ & 1 & $.314^{* *}$ \\
\hline & Sig. (2-tailed) N & .000 & .000 & .000 & & .000 \\
\hline & & 275 & 275 & 275 & 275 & 275 \\
\hline \multirow{3}{*}{ nPow } & Pearson Correlation & $.208^{* *}$ & $.205^{* *}$ & $.283^{* *}$ & $.314^{* *}$ & 1 \\
\hline & Sig. (2-tailed) & .001 & .001 & .000 & .000 & \\
\hline & $\mathrm{N}$ & 275 & 275 & 275 & 275 & 275 \\
\hline
\end{tabular}

**. Correlation is significant at the 0.01 level (2-tailed).

As a result of the Pearson Correlation being positive, it is concluded that as the reward for knowledge $(r=0.408)$ or reward for skills increase $(\mathrm{r}=0.404)$, the Employee creative performance will also be increased. On the other 
hand, as the need for power increase $(r=0,314)$, the intrinsic motivation $(r=0.420)$ will increase and increasing also Employee creativity.

\subsection{Regression Analysis}

Simple and multiple regression analysis along with hierarchal regression analysis was used test the impact of each variable on dependent variable. Aiken and West (1991) have suggested that hierarchical regression analysis is the most appropriate method for investigating interaction effects. Hence, it was also used to examine the main and interacting effects of variables. The results are showing on the tables below.

- Hypothesis 1 predicted that reward for knowledge and reward for skills implementation would be positively related to creativity. The result in table 7 (Model 2) $\beta=.502, p<0.001$ showed that reward for skills was significantly and positively related to employee creativity with an Fvalue $=82.144$. Similarly, the result in table 7 (Model 3) $\beta=.323, p<0.001$ showed that reward for knowledge was significantly and positively related to employee creativity with Fvalue=29.604. Therefore, hypothesis 1 was supported.

- Hypothesis 2 predicted that intrinsic motivation mediates the relationship between reward for knowledge and employee creativity. The result in table 7 (Model 6) $\beta=.314, p<0.001$ showed that the relationship between reward for knowledge, the mediating variable Intrinsic motivation and the dependent variable employee creativity was positive and significant. Indeed, when we add the mediating variable into the existing variables of reward for knowledge reflecting into employee creativity, we can see in table 7 that the R square of reward for knowledge change and increase from 0.098 to 0. 167.Therefore, hypothesis 2 was supported.

- Hypothesis 3 predicted that intrinsic motivation mediates the relationship between reward for skills and employee creativity. The result in table 7 (Model 5) $\beta=.216, p<0.001$ showed that the relationship between reward for skills, the mediating variable Intrinsic motivation and the dependent variable employee creativity was positive and significant. Indeed, adding intrinsic motivation as a mediator in the existing relationship between reward for skills and employee creativity we can see how the $\mathrm{R}$ square $=0.231$ shifted to be 0.264 . Therefore, hypothesis 3 was supported.

Table 7. Regression Models: the mediating role of intrinsic motivation on the relationship between Reward for skills/knowledge and employee creativity

\begin{tabular}{|c|c|c|c|c|c|c|c|}
\hline \multicolumn{2}{|c|}{ Statistics } & \multicolumn{6}{|c|}{ Employee creativity } \\
\hline & & Model 1 & Model2 & Model 3 & Model 4 & Model 5 & Model 6 \\
\hline \multirow[t]{9}{*}{ B } & Gender & 0.134 & 0.057 & 0.084 & 0.056 & 0.051 & 0.071 \\
\hline & Age & $0.349^{-\cdots}$ & 0.164 & $0.252^{\cdots}$ & $0.168^{\cdots}$ & $0.156^{\cdots}$ & $0.222^{\circ}$ \\
\hline & Degree of education & -0.056 & -0.014 & -0.037 & -0.015 & -0.015 & -0.034 \\
\hline & Occupation & -0.078 & -0.062 & $-0.067^{\cdots}$ & -0.061 & $-0.063^{2}$ & $-0.067^{-\ldots}$ \\
\hline & Years of working & 0.105 & 0.028 & 0.082 & 0.034 & 0.050 & 0.097 \\
\hline & $\begin{array}{l}\text { Monthly Average } \\
\text { income }\end{array}$ & $0.195^{\cdots \cdots}$ & 0.114 & $0.133^{\cdots \cdots}$ & $0.111^{\cdots \cdots}$ & $0.104^{\cdots \cdots}$ & $0.118^{-*}$ \\
\hline & Rewards for skill & & 0.502 & & 0.439 & 0.409 & \\
\hline & $\begin{array}{l}\text { Rewards for } \\
\text { knowledge }\end{array}$ & & & 0.323 & 0.138 & & $0.186^{-\ldots}$ \\
\hline & Intrinsic motivation & & & & & 0.216 & 0.314 \\
\hline \multirow{3}{*}{\multicolumn{2}{|c|}{$\begin{array}{l}\mathrm{R}^{2}(f \\
\mathrm{F} \\
\mathrm{R}^{2}\end{array}$}} & 0.261 & 0.228 & 0.095 & 0.264 & 0.259 & 0.161 \\
\hline & & 17.103 & 82.144 & 29.604 & $39.097^{\circ}$ & $35.977^{\cdots}$ & 27.322 \\
\hline & & 0.277 & 0.231 & 0.098 & 0.540 & 0.264 & 0.167 \\
\hline
\end{tabular}

$\mathrm{N}=275, * \mathrm{p}<0.05 ; * * \mathrm{p}<0.005 ; * * * \mathrm{p}<0.001$.

- Hypothesis 4 predicated that the need for power moderates the relationship between intrinsic motivation and employee's creativity such that individuals with a high need for power will be more intrinsically motivated to exhibit greater creativity. Result in table 8 (model 9) $\beta=.34, p<0.05$ showed that the interaction term of need for power and intrinsic motivation was positively significant with employee creativity. In addition, the figure 1 reveal that employee creativity was higher for individual high in need for power than those low in need for power. Therefore, hypothesis 4 was supported. 
Table 8. Regression Models: the moderating role of need for power on the relationship between intrinsic motivation and employee creativity

\begin{tabular}{|c|c|c|c|c|}
\hline \multirow[t]{2}{*}{ Statistics } & & \multicolumn{3}{|c|}{ Employee creativity } \\
\hline & & Model 7 & Model 8 & Model 9 \\
\hline \multirow[t]{9}{*}{$\bar{\beta}$} & Gender & 0.134 & 0.057 & 0.084 \\
\hline & Age & $0.349^{\cdots \cdots}$ & $0.164 \cdots$ & 0.252 \\
\hline & Degree of education & -0.056 & -0.014 & -0.037 \\
\hline & Occupation & -0.078 & -0.062 & -0.067 \\
\hline & Years of working & 0.105 & 0.028 & 0.082 \\
\hline & Monthly Average income & $0.195^{\ldots \ldots}$ & 0.114 & 0.133 \\
\hline & Intrinsic motivation & & 0.27 & 0.27 \\
\hline & Need for power & & 0.43 & 0.44 \\
\hline & IM*nPow & & & 0.34 \\
\hline \multirow{3}{*}{$\begin{array}{l}\mathrm{R}^{2}(\text { Adj }) \\
F \\
\mathrm{R}^{2}\end{array}$} & & 0.261 & 0.228 & 0.095 \\
\hline & & 17.103 & 82.144 & 29.604 \\
\hline & & 0.277 & 0.231 & 0.098 \\
\hline
\end{tabular}

$\mathrm{N}=275, * \mathrm{p}<0.05 ; * * \mathrm{p}<0.005 ; * * * \mathrm{p}<0.001$.

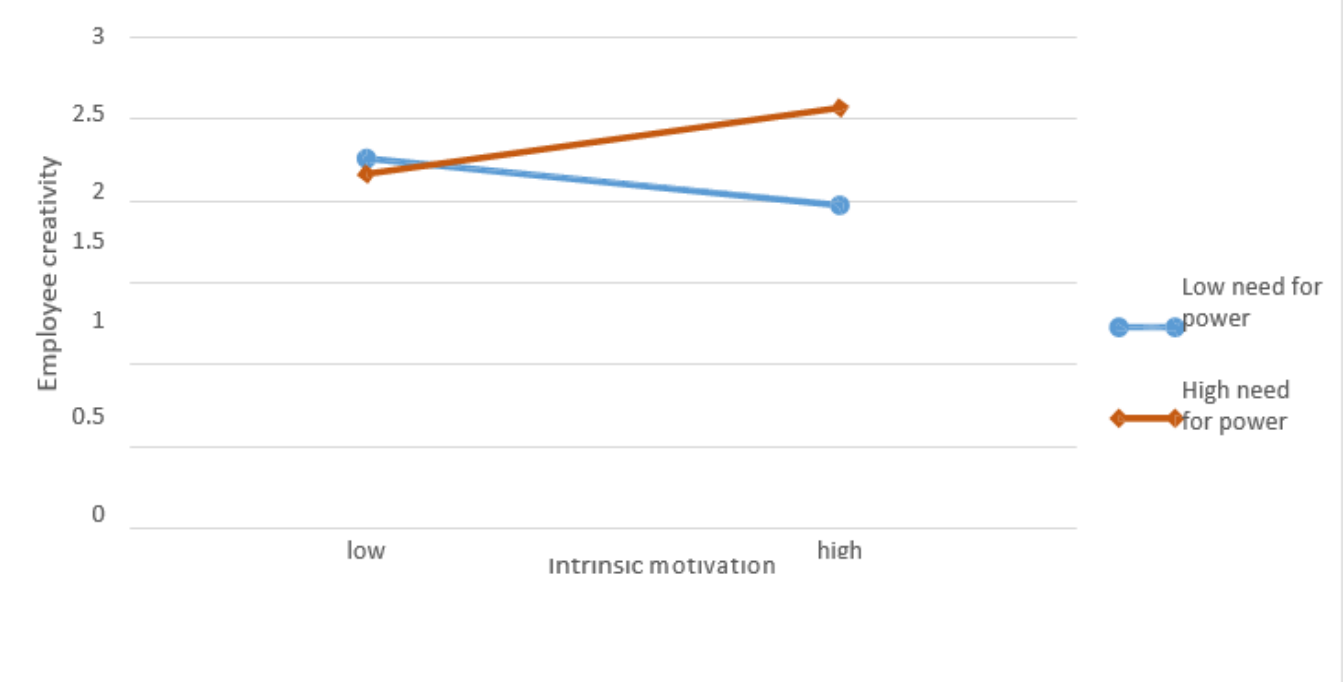

Figure 1. need for power as a moderation on the relationship between intrinsic motivation and employee creativity

\section{Discussion}

The main objective of this study was to examine the effects that can have reward on stimulating creativity especially reward for knowledge and reward for skills. However, four hypotheses were established and tested by using simple and multiple hierarchical regressions. The findings revealed that reward for knowledge and reward for skills effect on employee creativity was positive and significant. Therefore, the use of reward for knowledge or reward for skills can help to stimulate or increase employee creativity. As it was found by previous study of Eisenberger \& Rhoades (2001) reward increase creativity. And also helps to increase employee performance by enhancing employee skills, knowledge and abilities in order to achieve organizational objectives according to the study findings of Ajila and Abiola (2004). Hypothesis 1 was supported in table 7. The outcome of this study indicated that reward for skills has a strong effect on employee creativity more than the reward for knowledge based on the result shown in table7 (Model 4). Similarly, research has suggested that contextual variables, and particularly reward associated with individual competence, may be more effective predictors of employee creativity according to Shalley \& Oldham (1997).

Additionally, the mediating effect of intrinsic motivation in the relationships between reward for knowledge with employee creativity and reward for skills with employee creativity was also examined in this study, the 
mediating effect of intrinsic motivation has been revealed to be positive and significant in the two relationships. Indeed, Individuals are likely to be most creative when they experience high levels of intrinsic motivation According to (Amabile, 1996; Audia \& Goncalo, 2007; Armstrong and Murlis, 2004). Research by Amabile (1996) pointed out that "rewards can actually enhance intrinsic motivation and creativity when they confirm competence, provide useful information in a supportive way, or enable people to do something that they were already motivated to do" Therefore intrinsic motivation can be considerate as a mediator of the relationships between reward for knowledge and reward for skills with employee creativity. Hypothesis 2 and 3 were supported in table 7 and table D2 (annex).

We took a deeper adventure to analyze the relationship between intrinsic motivation and employee creativity by adding the need for power in the equation as a moderator. The result of hypothesis four shown that the moderating effect of need for power was positively and significantly related to the relationship between intrinsic motivation with employee creativity. The need for power will help to increase intrinsic motivation for a great creativity. As it has been shown on figure 1 the moderating variable has elevated the current weight that was present on intrinsic motivation for a high creativity. We can also see on table E4 (annex) how the significance of intrinsic motivation $\mathrm{P}>0.05=0.06$ shifted to being $\mathrm{p}<0.01=0.00$. Indeed, studies show that power leads to increased creativity (Galinsky, Magee, Gruenfeld, and Whitson, 2008, Smith \& Trope, 2006). Furthermore, individuals with a high need for power are intrinsically motivated to perform tasks. They are likely to tap every opportunity to achieve their needs, with creativity appearing to be a way of meeting these needs. Therefore, the need for power of worker will help him to increases his intrinsic motivation in order to increase his creative performance. Hypotheses 4 was supported.

However, all the hypotheses were strongly supported. Thus, Managers should thirst trying to know the needs of their employees and answering in order to motivate them to achieve a high creative performance as it was said by Chughtai (2008) identifying the needs and answering it is the most basic approach of every organization to earn the commitment of the employees. The componential theory of creativity introduced by Amabile (1996) underscores the role of motivation in enhancing or reducing individuals' creativity. Based on this theory, an individual could display higher levels of creativity when three components are present: (1) the individual needs to have pertinent knowledge and skills; (2) he/she should have relevant creativity skills and strategies, (3) h/she should be intrinsically driven to work on the task. Amabile (1996) defined intrinsic motivation as the kind of motivation that originates from individuals' interest and involvement in the task itself. The third component, intrinsic motivation was argued to be crucial for creativity, since it helps engage and persist in creative activities. The componential theory provides the ground for studying employee creativity using a motivational approach and highlighting the value of intrinsic motivation.

\section{Conclusion}

Today's, organizations are operating in a very dynamic and highly competitive environment, to remain relevant in the market, they have to be able to respond quickly to ever changing customer demands.

Reward system is one of the ways used by organizations for attracting and retaining suitable employees as well as facilitating them to improve their performance. The management has established rewards in their organization in pursuit of increasing employee performance so as to ensure prompt and quality service. The Purpose of this study was to examine the effect of reward on employee creativity specifically reward for knowledge and reward for skills. Based on the findings, the study concludes that both of them have significant and positive effect on employee creativity. Indeed, reward of skills has proven to be more susceptible to boost employee creativity than reward for knowledge. The study found that the relationship between reward and creativity can be mediated by employee intrinsic motivation to increase creativity because individual creativity is a function of knowledge acquisition and motivation. The study reveals again that this motivation could be moderated by an.

\section{Acknowledgments}

First, we give thanks to the Almighty God for His grace and guidance which saw us through to successfully complete this paper. Our noteworthy acknowledgement also goes to our able supervisor, Professor Guangjun Xing and Professor Wei Jianglu for their constructive critique which sustained us to complete this paper. We also appreciate the support and cooperation of the employees from Zhongxing Telecommunication Equipment (ZTE), Baidu, Roche. We thank our family and friends, who provided an enabling environment which assisted and encouraged us to successful complete my paper. 


\section{References}

Aiken, L. S., \& West, S. (1991). Multiple regression: Testing and Interpreting Interaction. Sage

Ajila, C., \& Abiola A. (2004). Influence of rewards on work performance in an organization. J.Soc.sci, 8(1), $7-12$.

Alpander, G. G. (1991). Developing manager' ability to empower employees. Journal of Management Development, 10, 13-24. https://doi.org/10.1108/02621719110142887

Amabile, T. M. (1990). Within you, without you: The social psychology of creativity, and beyond.

Amabile, T. M. (1996). Creativity in context. Boulder, CO: WestwardPres.

Amabile, T. M. (1996). The Motivation for Creativity in organizations. Harvard business school, background. Prod. \# 396240 Retrieved on January 7, 2019 from: https://cb.hbsp.harvard.edu/cbmp/content/396240-PDF-ENG

Amabile, T., Conti, R., Coon, H., Lazenby, J., \& Herron, M. (1996). Assessing the work environment for creativity. Academy of Management Journal, 39(5), 1154-1184.

Anderson, N., Potoc `nik, K., \& Zhou, J. (2014). Innovation and creativity in organizations: A state-of-the-science review, prospective commentary, and guiding framework. Journal of Management, 40, 1297-1333. https://doi.org/10.1177/0149206314527128

Armstrong, M., \& Murlis, H. (2004). Reward management: a handbook of remuneration strategy and practice, Kogan Page Limited, London.

Armstrong, M., \& Murlis, H. (2007) Reward management: a handbook of remuneration strategy and practice. 5 th rev ed. London: Kogan Pag.

Atchison, T. A. (2003). Exposing the myths of employee satisfaction. Healthcare Executive, 17(3), 20.

Audia, P. G., \& Goncalo, J. A. (2007). Past success and creativity overtime: A study of inventors in the hard disk drive industry. Management Science, 53, 1-15. https://doi.org/10.1287/mnsc.1060.0593

Azar, M., \& Shafighi, A. (2013). The Effect of Work Motivation on Employees' Job Performance: International Journal of Academic Research in Business and Social Sciences, 3(9). ISSN: 2222-6990.

Beardwell, J., \& Claydon, T. (2007). Human Resource Management. A Contemporary Approach. (5th ed.). Harlow: Prentice Hall.

Chughtai, A. A. (2008). Impact of Job Involvement on In-Role Job Performance and Organizational Citizenship Behaviour. Journal of Behavioral and Applied Management, 9.

Cronbach, L. J., \& Meehl, P. E. (1955). Construct Validity in Psychological Tests. Psychological Bulletin, 52, 281-302. https://doi.org/10.1037/h0040957

Deci, E. L., \& Ryan, R. M. (2000). Intrinsic and Extrinsic Motivations: Classic Definitions and New Directions. Contemporary Educational Psychology, 25, 54-67. https://doi.org/10.1006/ceps.1999.1020

Deci, E. L., Koestner, R., \& Ryan, R. M. (1999). A meta-analytic review of experiments examining the effects of extrinsic rewards on intrinsic motivation. Psychological Bulletin, 125, 627-668. https://doi.org/10.1037/0033-2909.125.6.627

Dierdorff, E. C., \& SurfaceIf, E. A. (2008). You Pay for Skills; Will They Learn? Skill Change and Maintenance Under a Skill-Based Pay System, 34(4), 721-743.

Eisenberger, R., \& Aselage, J. (2009). Incremental effects of reward on experienced performance pressure: positive outcomes for intrinsic interest and creativity, 30(1), 95-117.

Eisenberger, R., \& Rhoades, L. (2001). Incremental effects of reward on creativity. Journal of Personality and Social Psychology, 81, 728-741. https://doi.org/10.1037/0022-3514.81.4.728

Eisenberger, R., Armeli, S., \& Pretz, J. (1998). Can the promise of reward increase creativity? Journal of Personality and Social Psychology, 74, 704-714. https://doi.org/10.1037/0022-3514.74.3.704

Fairbank, J. F., \& Wiliams, S. D. (2001). Motivating Creativity and Enhancing Innovation through Employee Suggestion System Technology, 10(2), 68-74.

Ford, C. \& A. Gioia, D. (2000). Factors Influencing Creativity in the Domain of Managerial Decision Making. Journal of Management - J MANAGE, 26, 705-732. https://doi.org/10.1177/014920630002600406 
Galinsky, A. D., Magee, J. C., Gruenfeld, D. H., \& Whitson, J. A. (2008). Power Reduces the Press of the Situation: Implications for Creativity, Conformity, and Dissonance, Journal of Personality and Social Psychology, 95(6), 1450-1466. https://doi.org/10.1037/a0012633

Gefen, D., Straub, D., \& Marie-claude, B. (2004). Validation Guidelines for IS Positivist Research. Communications of the Association for Information Systems, 3.

Guay, F., Vallerand, R. J., \& Blanchard, C. (2000). On the assessment of state intrinsic and extrinsic motivation: The situational motivation scale (SIMS). Motivation and Emotion, 24, 175-213. https://doi.org/10.1023/A:1005614228250

Hennessey, B. A., \& Amabile, T. M. (1998). Reality, intrinsic motivation, and creativity. Am. Psychol., 53, 674-675. https://doi.org/10.1037/0003-066X.53.6.674

Hennessey, B. A., Amabile, T. M. (1990). Consensual assessment. In Encyclopedia of Creativity, ed. M Runco, S Pritzker, pp. 34-36. New York: Academic.

Herzberg, F. (1957). The motivation to work. New York; Wiley.

Hinton, P. R., Brownlow, C., McMurray, I., \& Cozens, B. (2004). SPSS explained. Routledge Inc., East Sussex, England. https://doi.org/10.4324/9780203642597

Hon, Alice, H. Y., \& B. Rensvold, R. (2006). An interactional perspective on perceived empowerment: The role of personal needs and task context. The International Journal of Human Resource Management, 17. 959-982. https://doi.org/10.1080/09585190600641271

Janssen, O., \& Van Yperen, N. (2004). Employees' Goal Orientations, the Quality of Leader-Member Exchange, and the Outcomes of Job Performance and Job Satisfaction. The Academy of Management Journal, 47, 368-384.

Martindale, C. (1989). Personality, Situation, and Creativity. New York: Plenum. https://doi.org/10.1007/978-1-4757-5356-1_13

McClelland, D. C. (1987). Human motivation. Cambridge England; New York: Cambridge University Press.

Nationalencyklopedin (2015). Beloning. Collected 2018-12-29, from: http://www.ne.se/uppslagsverk/ordbo/svensk/beloning

Nunnally, J. C., \& Bernstein, I. H. (1994) The Assessment of Reliability. Psychometric Theory, 3, 248-292.

Pirola-Merlo, A., \& Mann, L. (2004) The Relationship between Individual Crea-tivity and Team Creativity: Aggregating across People. Journal of Organizational Behavior, 25, 235-257. https://doi.org/10.1002/job.240

Shalley, C. E., \& Oldham, G. R. (1997). Competition and creative performance: Effects of competitor presence and visibility. Creativity Research Journal, 10, 337-345. https://doi.org/10.1207/s15326934crj1004_5

Shin, S. J., \& Zhou, J. (2003). Transformational Leadership, Conservation, and Creativity: Evidence from Korea. The Academy of Management Journal, 46(6), 703-714. https://doi.org/10.5465/30040662

Smith, P. K., \& Trope, Y. (2006). You focus on the forest when you're in charge of the trees: Power priming and abstract information processing. Journal of Personality and Social Psychology, 90, 578-596. https://doi.org/10.1037/0022-3514.90.4.578

Sternberg, R. J., \& Lubart, T. I. (1996). Investing in creativity. American Psychologist, 51(7), 677-688. https://doi.org/10.1037/0003-066X.51.7.677

Van Dijk, C., \& Van den Ende, J. (2002). Suggestion systems: Transferring employee creativity into practicable ideas. $R \&$ D Management, 32, 387-395. https://doi.org/10.1111/1467-9310.00270

\section{Copyrights}

Copyright for this article is retained by the author(s), with first publication rights granted to the journal.

This is an open-access article distributed under the terms and conditions of the Creative Commons Attribution license (http://creativecommons.org/licenses/by/4.0/). 